\title{
Access as an enabler and an obstacle to nurse's use of ICT during the COVID-19 pandemic: Results of a national survey
}

\author{
Emma Collins ${ }^{1,2}$, MN, PgCert HE, BEd, RN, Professional \\ Practice Fellow \\ Michelle Honey ${ }^{3}, \mathrm{RN}, \mathrm{PhD}$, Senior Lecturer, School of \\ Nursing University of Auckland \\ ${ }^{1}$ Women's and Children's Health, University of Otago, Dunedin, \\ Aotearoa New Zealand \\ ${ }^{3}$ University of Auckland, Auckland, Aotearoa New Zealand \\ 2Corresponding Author: emma.collins@otago.ac.nz
}

\author{
Citation \\ Collins, E., \& Honey, M. (2021). Access as an \\ enabler and an obstacle to nurse's use of ICT \\ during the COVID-19 pandemic: Results of a \\ national survey. Nursing Praxis in Aotearoa New \\ Zealand, 37(3), 62-70. \\ https://doi.org.10.36951/27034542.2021.036
}

\begin{abstract}
The COVID-19 global pandemic has altered the way people in Aotearoa New Zealand live, work, play, and access healthcare, and this has included an increase in the use of technology. The aim of this exploratory study was to understand Aotearoa New Zealand nurses' use of technology during the COVID-19 lockdown, in particular what information and communication technologies (ICT) was being used and how nurses felt about using ICT in their practice. An anonymous online survey, utilising both open and closed-ended questions, was selected as an appropriate and safe data collection method during the pandemic. Snowball sampling was used with an online survey that was sent out during the level 3 lockdown (from March to May 2020) via social media and existing email networks and so potentially dispersed to nurses throughout Aotearoa New Zealand. In total 220 responses were received. The results were analysed using descriptive statistics, and open-ended qualitative comments were thematically analysed. The key finding was that there were significant access issues related to nurses using ICT in their practice: Access to information technology systems and resources, access to technical support, access to connectivity (particularly for those working from home in rural communities) and access to patients and colleagues. As predicted, this study has identified areas for future exploration but highlights Aotearoa New Zealand nurse's ability and willingness to embrace technology to better meet the needs of their patients.
\end{abstract}

Keywords / Ngā kupu matua: access to technology / noho wātea ki te hangarau; COVID-19; ICT; technology / hangarau; nursing / mahi tapuhi

\section{Te Reo Māori translation}

\section{Ko te noho wātea hei ara tīmata, hei tauārai hoki ki te whakamahinga a tētahi tapuhi i ICT i te urutā o Covid-19: Ngā kitenga o tētahi uiuinga ā-motu}

\section{Ngā ariā matua}

Nā te urutā COVID-19 kua rerekē te noho, te mahi, te tākaro, te urutomo ki ngā tautiaki hauora, o te tangata i Aotearoa New Zealand, nā konei kua piki ake te whakamahinga hangarau. Ko te whāinga o tēnei tirohanga kia mārama ki te whakamahinga a ngā tapuhi o Aotearoa i ngā hangarau i ngā rā o te katinga mō COVID-19, arā, he whai kia mārama ko ēhea ngā mōhiotanga me ngā whakawhiti (ICT) e whakamahia ana, he pēhea hoki ngā whakaaro o nga tapuhi mō ICT i tā rātou mahi. I whiria tētehi rangahau tuihono, me te whakamahi tikanga kohi raraunga hāngai, haumaru hoki, i ù rā ki ngā pātai tuwhera me ngā pātai mutu. I whakamahia tētahi tikanga tīkaro pūputu mā tētahi uiuinga tuihono, i tukua atu i roto i te katinga taumata 3 (mai i Poutūterangi/Māehe ki Haratua/Mei 2020) mā ngā paepori me ngā whatunga īmēra kua tū kē, nā reira, i tae atu pea ki ngā tapuhi puta noa i Aotearoa. 220 ngā whakautu i tae mai, huia katoatia. I tātaritia ngā hua nā te whakamahi i ngā tatauranga whakamārama, me i āta tātaritia ngā whakapuaki kounga tuwhera, i runga i ngā kaupapa o roto. Ko te kitenga matua, 
tērā ētahi take tauārai i ngā tapuhi e whakamahi ana i te ICT i roto i ā rātou mahi: Ko te noho wātea mai o ngā pūnaha me ngā rauemi hangarau mōhiotanga, te noho wātea o ngā tūhono ipurangi (otirā mō te hunga mahi i te kāinga me ngā hapori i te tuawhenua, he mea hira tēnei) me te noho wātea mai o ngā tūroro me ngā hoa. I runga anō i ngā matapae, kua kitea ētahi āhuatanga hei mātai anō i roto i tēnei rangahau, heoi anō ka kitea i roto te kaha me te kaingākau o ngā tapuhi ki te hāpai i te hangarau tika hei manaaki i ā rātou tūroro.

\section{Introduction}

The number of cases and impact of COVID-19 globally continues to rise with the World Health Organization (WHO) (2021a) reporting a cumulative 265 million cases and over 5.2 million deaths by December 2021. Nurses have, and continue to play, an essential role in every country's response to the pandemic and a reliance on technology has formed part of each country's response (Buheji, \& Buhaid, 2020; Bokolo, 2021; Dykes \& Chu, 2021).

The impact of COVID-19 on nurses has resulted from concerns for their patients but also their own, and their family's safety (Buheji \& Buhaid, 2020; Jackson, et al., 2020). Nurses have been required to use new technologies in unique ways to provide care (Dykes \& $\mathrm{Chu}$, 2021). The use of information and communication technologies (ICT) in healthcare, has been quickly adopted during this global emergency, and can be a convenient, safe, scalable and effective method of providing clinical care (Bokolo, 2021). Nursing use of ICT in this context is defined as "the use of computers, information and communication technologies to support nursing practice" (Honey, Collins, \& Britnell, 2018, p. 4). This broad definition therefore includes nurses wherever they are working, including in management, education, research, the community, or across primary, secondary or tertiary care. Many nurses have had to rapidly adjust the way they practice and adapt quickly to new working conditions which has included engaging with ICT (Holmes, 2020).

Nurses in many clinical settings have had to change how they interact with patients (Bostock-Cox, 2020). For example, instead of having a face-to-face consultation in a clinic, many virtual consultations have taken place over the telephone or using video conferencing software such as Skype or Zoom (Meehan \& Honey, 2020). One example of the use of ICT in healthcare is telehealth, which is defined as "health care delivered using digital technology where participants may be separated by time and/or distance" (New Zealand Telehealth Forum and Resource Centre, 2021, para 1). Telehealth, which may use phone, tablet, or computer audio and video conferencing modes to communicate, can limit the nurse's and patient's exposure while giving the opportunity to provide care (Bokolo, 2021). The WHO Global Strategic Directions for Nursing and Midwifery 2021-2025 (2021b) supports the use of telehealth, recognising that it can provide protection from occupational hazards. Data and technology may also be used for calculating safe staffing levels, decision-support, improved referral mechanisms, to support nurses working in remote and isolated settings and for integration of health services across the continuum of care (WHO, 2021b).

The COVID-19 pandemic has highlighted nurses use of ICT (Bostock-Cox, 2020; Dykes \& Chu, 2021). However, one of the concerns for nurses is their ability to provide and demonstrate care to their patients (Buheji \& Buhaid, 2020). Gunawan and colleagues (2020) suggest that using technology may be challenging and have the potential to limit the scope of nursing, noting that nurses use verbal and nonverbal communication, including physical touch, eye contact and gestures, in their interactions with patients to express empathy and to show understanding and respect. However, nurses have the communication skills and the adaptability to provide virtual assessments and meaningful interactions with their patients, though some additional planning may be needed (Meehan \& Honey, 2020).

The Ministry of Health (2021) provides ongoing information about COVID-19, with information on confirmed and probable cases, as well as vaccination rates. While Aotearoa New Zealand continues to report a relatively low number of cases and death rate there is still a concern about the potential impact of the COVID-19 pandemic, and particularly the Delta variant (Ministry of Health, 2021) and other emerging variants. Use of ICT is part of the national COVID-19 response, from the Âwhina and COVID Tracer app, the enhanced immunisation database through to technology to support all aspects of nursing practice such as video conferencing and robust databases. However, little was known about 
Aotearoa New Zealand nurses' use of ICT during the early stages of the pandemic, hence this study.

\section{Methods}

The aim of this exploratory study was to get an overview of how the early stages of the COVID-19 pandemic changed nurses use of ICT and how they felt about using ICT in their practice.

\section{Study Design}

A survey was selected for this study as these can be designed to capture data such as behaviours, attitudes and opinions (Polit \& Beck, 2017). To obtain an overview of nurses use and perceptions of ICT during the strictest period of COVID-19 quarantine (New Zealand Government, 2020) an online survey was considered the most appropriate method as it could reach nurses throughout the country while maintaining social distancing.

The survey was developed using questions that were drawn from literature and previous research, and were written to be relatable for nursing participants. For example, for one of the questions, terminology from popular nursing theorist Benner (2000) was used. Respondents were asked to determine whether they felt that they were a novice, an advanced beginner, competent, proficient or an expert. The well-known language from Benner (2000) was used purposefully to make the survey easy for the participants to complete. Both closed-ended questions, which were quick to click to answer, and open-ended questions for free text responses were included throughout the survey. Questions asked where the nurse had been working from (their usual work site, home, or another site); their self-assessed proficiency using ICT before and after the pandemic started; if their access and use of ICT had changed; what devices and applications they were using and for what purposes. In addition, statements were provided so nurses could indicate their awareness, compliance and if this had changed since the pandemic started, in relation to the need for security, preventing the spread of computer viruses and malware and how to clean hardware, such as phone and keyboards, to maintain their personal, patient and other staff safety. A final section asked nurses about the barriers they had experienced and their perceived benefits of using ICT. Where statements were provided a scale of responses were possible such as: strongly agree, agree, neither agree nor disagree, disagree, strongly disagree. It was possible to not answer some questions and others had multiple options that could be selected. Pilot testing of the final wording and flow of the questions was undertaken by four nurses before distribution. There were 15 substantive questions in the survey, some with sub-questions, and it was estimated it would take five to ten minutes to complete, so as not be too onerous on the nurses who chose to participate.

\section{Participants}

Participants were recruited using a snowball method, known to be effective in recruiting a hard-to-reach populations (Polit \& Beck, 2017). The inclusion criteria were that the person completing the survey was a registered nurse, currently practising in Aotearoa New Zealand during the COVID-19 level 3 and 4 lockdown period, which was from $11.59 \mathrm{pm}$ Wednesday 25 March until 11.59pm on Wednesday 13 May 2020 (New Zealand Government, 2020). Nurses known to the authors were invited to participate in the study on 22 April 2020, and to forward the survey onto others. The email included a link to the online anonymous Qualtrics survey. In addition, information and the link to the survey was posted on social media (Facebook, Twitter and LinkedIn).

\section{Ethical considerations}

Ethical approval for this study was obtained from Otago Polytechnic Ethics Committee (Ref: 2020.856). An incentive to participate was provided in the form of a donation for each completed survey to a national organisation that looks after the wellbeing of young New Zealanders. The link to the survey included participant information and submission of the survey was taken as consent. All responses were anonymous. Minimal demographic data was collected to protect anonymity.

\section{Data analysis}

Data analysis was completed using the collating and reporting options from Qualtrics, with additional descriptive statistical analysis using Excel. Comments from the open-ended questions were thematically analysed using the process outlined by Braun and Clarke (2006).

\section{Results}

A total of 220 responses were received. Quotes from participants are shown in italics. 


\section{Participant Demographics}

Demographic data (Table 1) shows that responses were received from nurses across New Zealand and from a variety of nursing practice settings.

Table 1: Demographic data; responses (n) and percentage $(\%)$

\begin{tabular}{lrc}
\hline & n & \% \\
\hline Geographical region of work & & 37 \\
Upper North Island & 82 & 18 \\
Lower North Island & 39 & 24 \\
Upper South Island & 53 & 21 \\
Lower South Island & 46 & \\
Main area of Nursing & & \\
Practice & 4 & 2 \\
Management & 22 & 10 \\
Education and Research & 96 & 44 \\
Primary Health Care & 28 & 13 \\
Secondary level care & 47 & 21 \\
Tertiary level care & 23 & 10 \\
Other & & \\
Location of work during L3 \& & & \\
4 Lockdown & 59 & $\mathbf{2 7}$ \\
Home & 123 & 56 \\
My normal work environment & 38 & 17 \\
Other & $\mathbf{2 2 0}$ & \\
\hline Total & & \\
\hline
\end{tabular}

The majority of participants had been working as a nurse for more than 15 years $(61 \%, n=132)$ suggesting that most were experienced nurses. When asked where they were working from during the level 3 and 4 lockdown, over half $(n=123 ; 56 \%)$ were working from their normal work environment, however some were working from home $(n=59$; $27 \%)$; with others $(n=38 ; 17 \%)$ indicating they had been being redeployed into community based assessment clinics (CBACs); other departments or facilities of the same organisation; or were working from multiple sites, such as home and workplace.

\section{ICT experience}

Participants were asked to rate their proficiency with ICT pre the COVID-19 outbreak and since the level 3 and 4 lockdown. This figure uses common nursing language from Benner (2000) to make the question easier to interpret. Figure 1 shows that that there was a small increase in the number of nurses who rated themselves as proficient and expert in ICT use from before COVID to the time of the survey.
Over half of participants ( $\mathrm{n}=117 ; 53 \%)$ felt that their access to technology had changed since the lockdown. Participants described using phone and video conferencing more often, being able to access particular systems and hardware from another location, and needing online access. Further comments included nurses having "minimal face to face contact", feeling that they are "reliant on technology to be able to do the job", and that "ICT is essential for communication".

Figure 1: Responses (n) to proficiency with ICT pre COVID-19 and post the level 3 and 4 lockdown

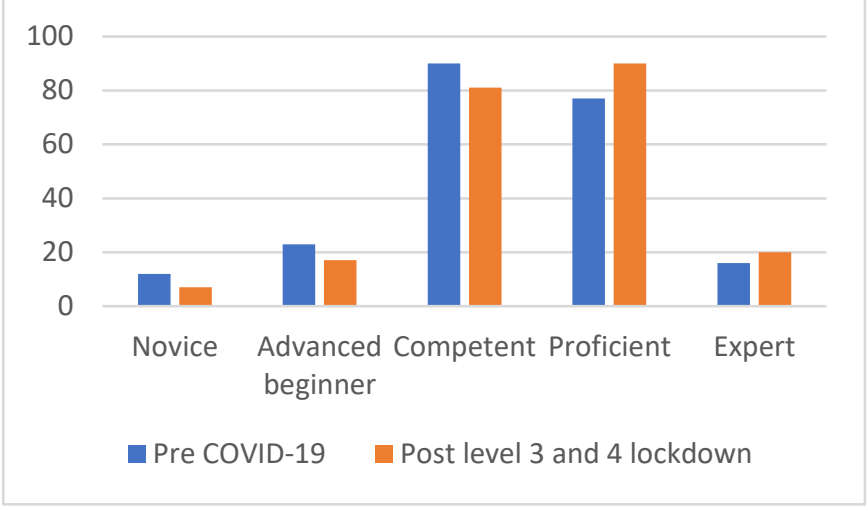

\section{ICT use}

Participants were asked what devices they had convenient use of during the level 3 and 4 lockdown for work purposes (Table 2). Multiple options could be selected. Nearly half $(n=131 ; 45 \%)$ reported already having access to all the devices they needed.

Table 2: Access to devices; number (n), percentage (\%)

\begin{tabular}{lrr}
\hline & n & \% \\
\hline Mobile phone (no internet) & 9 & 3 \\
Smart phone (with internet) & 42 & 15 \\
Tablet & 13 & 5 \\
Laptop & 36 & 13 \\
Desktop computer & 31 & 11 \\
Other & 23 & 8 \\
Not applicable/ & 131 & 45 \\
$\begin{array}{l}\text { I already had access to all the } \\
\text { devices I needed }\end{array}$ & \\
\hline
\end{tabular}

Communication was a key part of providing appropriate healthcare during the level 3 and 4 lockdown. Nurses indicated a range of applications and software were used to support communication with an increase in the use of phone and video (Figure 2 ). This communication was mostly with other nurses and health professionals (41\%), and with patients and their families (28\%). 
Figure 2: Responses (n) to communication applications (software) use

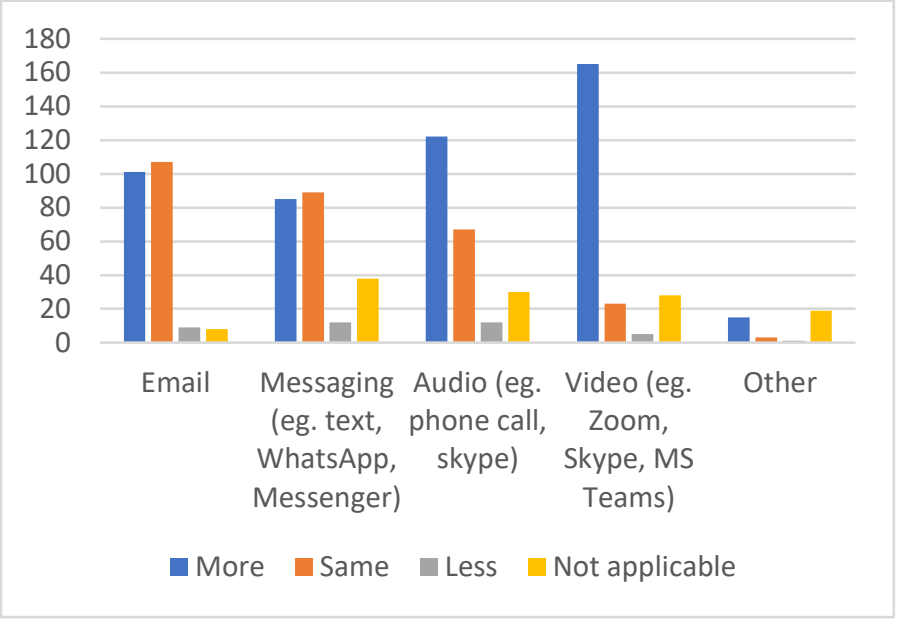

When asked to identify the main obstacles they experienced in relation to making more use of ICT nearly a quarter ( $\mathrm{n}=74 ; 22 \%)$ reported no obstacles, though having an unreliable connection to the internet was the most common obstacle $(n=60 ; 18 \%)$ (Table 3).

\section{Safety when using ICT}

Nurses were asked to indicate their awareness of the need for ICT safety in relation to security, including not sharing passwords; preventing corruption by computer viruses and malware; and how to clean hardware to maintain personal, patient and staff safety during the pandemic (Figure 3 ).
Table 3: Obstacles to making more use of ICT; number (n), percentage $(\%)$

\begin{tabular}{lcc}
\hline & $\mathbf{n}$ & $\mathbf{\%}$ \\
\hline I have no obstacles & 74 & 22 \\
Unreliable connection to the internet & 60 & 18 \\
Don't know how to use properly & 40 & 12 \\
Lack of skill & 41 & 12 \\
Already overworked without the & 36 & 11 \\
burden of ICT use & & \\
Takes me too long & 26 & 8 \\
& & \\
Fear or anxiety about using ICT & 11 & 3 \\
Other & 47 & 14 \\
\hline Total & 335 & \\
\hline
\end{tabular}

Figure 3: Nurses awareness of ICT safety

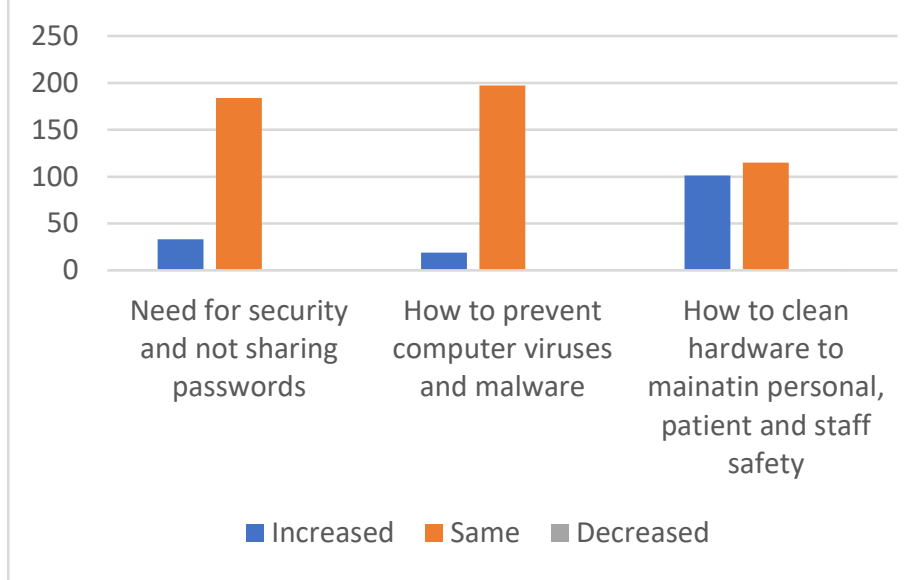

Figure 4: Nurses' perceptions about ICT use

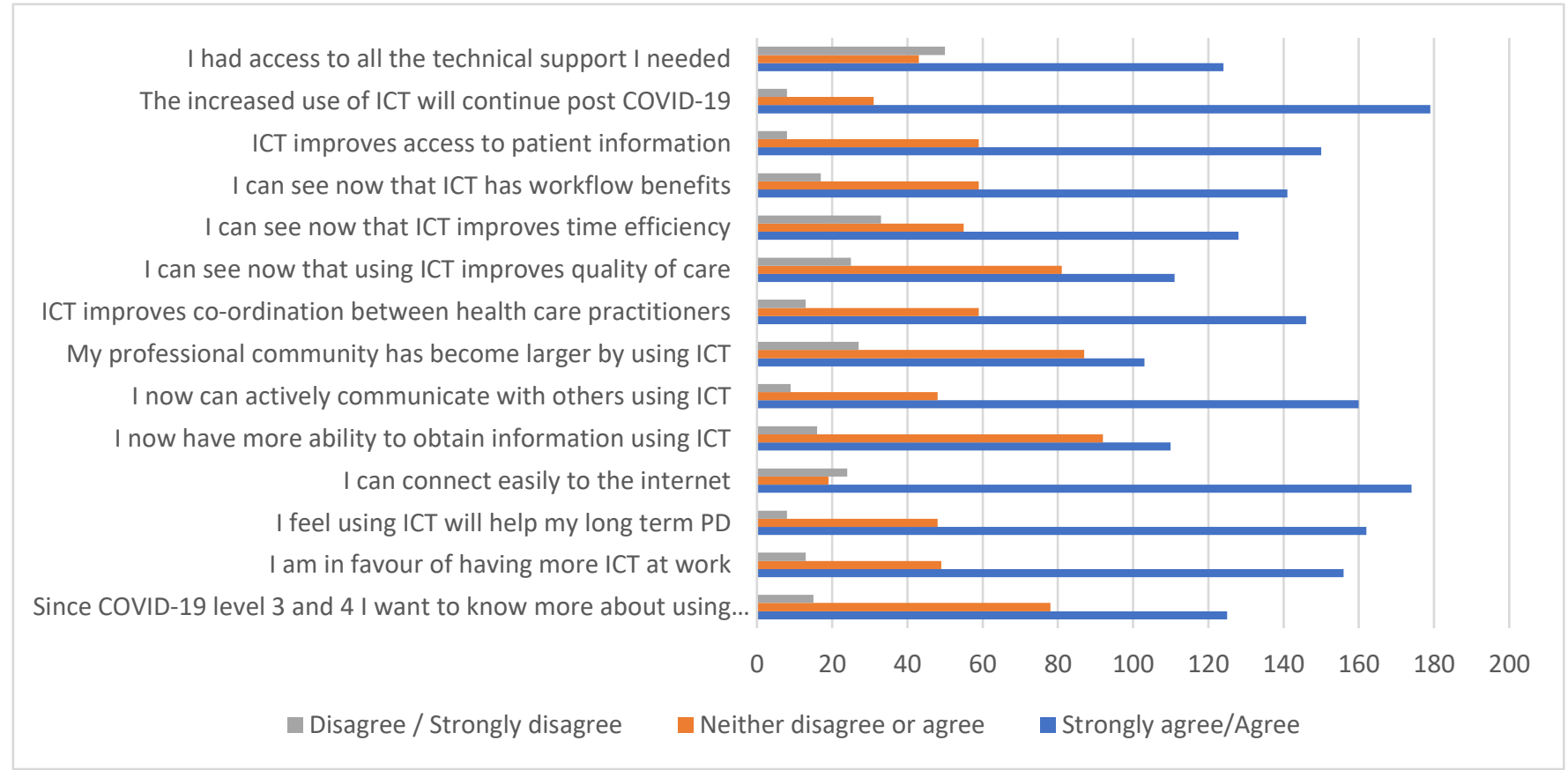




\section{ICT perceptions}

Nurses were asked on a five-point scale to indicate their level of agreement to twelve statements related to ICT use. These are reported with strongly agree and agree, and strongly disagree and disagree combined (Figure 4).

\section{Thematic analysis results}

Thematic analysis across the open-ended responses identified that the use of ICT has played a significant role in the delivery of healthcare during the pandemic. Nurses indicated benefits of using ICT and looking at the future considered that "the patient needs continue to be at the centre of what we do", and that "patient-led ICT use is important." Other responses included nurses "enjoyed the flexibility of being able to work from home"; felt there was "increased productivity"; that their "team was now stronger for being able to connect using ICT"; that the pandemic had "forced people who were resistant to ICT changes to 'get on board'"; and that they wanted "to see the changes made to their practice" through ICT to continue.

The analysis identified the dominant theme of access, with access both being seen as an obstacle and an enabler. This theme was further broken down into five sub-themes: access to people; access to support; access to resources; access to connectivity; and access to systems.

\section{Access to people}

Access to people was the main sub-theme and this included access to colleagues as well as patients. Video conferencing and communication tools such as MS Teams, Zoom, and Messenger were widely commented on and that they were becoming an acceptable part of daily nursing practice.

\section{Communication via the use of technology has become more accepted from within the organisation and when working with patients. It is now acceptable to use cellphones for texting or sending pictures, Zoom meetings, emails, MS [Microsoft] teams. This has also paved the way for rapid change that needed to happen but was stalled due to bureaucracy. [P125]}

In particular, being able to communicate with colleagues, while being physically distanced, was an enabler to ensuring work continued, with one nurse stating:
All my colleagues who had resisted IT are now on board and loving using Zoom to connect. I think our team is stronger for it. [P132]

While there has been a reliance on technology for communication for some this has also been challenging at times for both nurses and the patients they are trying to care for. As one nurse explained:

[It can be difficult] relying on technology to communicate... and for providing support and assessment of patients when triaging so we can determine if a visit is required. [P217]

However, nurses were clear that they preferred faceto-face contact, and that ICT was not a replacement for hands-on care, and whatever they did patients were always at the centre which was described by a nurse saying: "Using ICT doesn't perfectly replace face-to-face contact." However, ICT was also described as a barrier:

\section{It has worked well for those who have the resources and are able to video conference. Unfortunately, it is not so good for those without resources whom I was unable to connect with due to lack of video capable devices and/or were unable to respond to attempts to connect due to lack of credit on their phones. [P35]}

\section{Access to support}

While some staff adapted quickly to the changes needed, as evidenced by a nurse manager saying: "I feel extreme pride in my staff with their flexibility, resilience and adaptability", others did not: "there was an inability of staff to adapt to different ways of doing things." The amount of change required varied: "There has been absolutely no change in IT for me at work"; while for others the change has been significant: "I am feeling a lot more competent in using the laptop, etc off site." Coping with the increased use of ICT was often determined by access to support to manage devices and software. As one nurse described:

For at least a couple of weeks I had no access to a work computer... After getting the laptop my access continues to be impeded by IT issues that weren't solved for about another week or so. [P88]

Another nurse commented on "the lack of support," while a further nurse considered "our IT services have been inundated". 


\section{Access to resources}

Nurses had a number of challenges accessing resources such as computers and mobile devices to be able to do their job with nurses saying "[there was] a lack of technological equipment", and "I had to request a smart phone in order to be able to access different mediums such as WhatsApp, Zoom, etc". Whilst for some nurses resources were provided, others had to use their own devices, with associated costs:

I have had to purchase a laptop to be able to work from home ... This was essential to be able to continue to provide telehealth to patients. [P146]

Furthermore, one nurse shared that access to resources was not always equitable saying:

I am not supplied with the same hardware as the doctors, but have been advised that I have access to devices of my own that I can use. [P116]

Some nurses even stated that they had been requesting and needing access to particular IT resources for some time but it was only when this pandemic arrived that they were able to get these:

It just amazed me how quick management agreed to and rolled out access [to ICT]... after years of being told we couldn't have it because of cost. [P218]

For other nurses, there was no change at all to the resources that they needed or the way they worked: "We work in a virtual health setting so we have been prepared for this situation."

\section{Access to connectivity}

Being able to connect to the internet was often described as essential during the lockdown, but for many reliable fast internet to support working from home was assumed. Nurses reported reliable connectivity to the internet was challenging with nurses saying: "My home internet (rural) also has an effect on my ability to work normally," and:

Working remotely has not been a problem in the past but I'm unable now to use Zoom due to a poor connection. [P30]

Internet access and cell phone coverage needs to improve on the West Coast as this was a real challenge at times when out in the community. [P166]
Connectivity was not only a challenge for nurses who lived and worked remotely as for some there were also financial implications:

I did not have internet at home, just very limited data on my prepaid phone only, but now I have had to get unlimited data and it is a personal cost to me. [P62]

There were some workplaces, however, who recognised the increased need for connectivity and ensured that staff had this:

We have been given access to mobile data so we can use telehealth for consults with patients and families. [P217]

\section{Access to systems}

The level 3 and 4 lockdown saw an immense pressure placed on healthcare IT systems by multiple people simultaneously accessing these platforms from a variety of locations as one nurse describes saying: "The systems were totally overloaded which prevented me gaining adequate access." This kind of access issue caused a number of difficulties for staff who were working remotely as well as for those who were working in their normal workplaces:

We were making phone calls to our clients. There were not enough phone lines out of the hospital. Systems went down regularly. [P192]

I have had to phone colleagues to access information on my behalf and they then phone me back. [P61]

Some workplaces were not prepared for their staff having to work remotely and therefore the systems could not cope:

Incompatibility of systems that are available for use were a problem. I am happy to use ICT for work purposes, but the ICT needs to be fast, reliable and relevant to care delivery - often it is none of these. [P128]

Nurses reported being given access to ICT systems necessary for them to work remotely from home.

In summary, nurses want to see the increased use of ICT continue as they felt that they had good access to colleagues and patients and could see more clearly the benefits of using ICT in their daily work. One nurses epitomised this saying:

I'd like folks to generally continue with using the ICT and not just give it up because 'we're back to normal'. We need to explore the 
impact, on patients, family/whānau, staff and systems, of the increased and different ways of using ICT through this period; identify what worked really well and keep that going, identify what didn't work so well and why, then plan to make it better, and identify the gaps. [P128]

\section{Discussion}

The level 4 and 3 lockdown in March and April of 2020 in response to the COVID-19 pandemic was a period of time in Aotearoa New Zealand where the face of healthcare changed dramatically as has been noted also by other countries (Bokolo, 2021). Nurses in this study had to quickly adapt to using ICT, sometimes for the first time, and again this was similar to nurses internationally (Dykes \& Chu, 2021). This study found that accessing ICT during the pandemic could augment care and be an enabler but accessing and using ICT was at times a barrier to providing care.

Access was the key finding in this study, which encompassed access to people, support, resources, connectivity, and systems. Access to people was often described in this study as relating to communication with patients. Nurses' concerns about ICT impacting their patient care has been identified in the literature (Buheji \& Buhaid, 2020; Gunawan, et al., 2020). The pandemic has also brought concerns about interacting with patients face-to-face. A British study in a mental health setting finding health professionals felt they had lost confidence in their ability to relate emotionally to others and that face masks and social distancing has a detrimental effect on communication (Eddy, 2021). Exploring the use of ICT and the COVID19 pandemic on Aotearoa New Zealand nurses' communication with patients and other health professionals is an area for further research.

While this study found access to support is important, Buheji and Buhaid (2020) also consider a problemsolving orientation helpful, which would make nurses less reliant on IT support. Bokolo (2021) goes further suggesting a robust and stable network, with consistent access, would reduce the need for IT support, but that also adequate IT support is imperative. Though IT systems that were designed to meet the needs of nurses and nursing practice, that are easy to access and use, would reduce the need for support (Buheji \& Buhaid, 2020; Dykes \& Chu, 2021). This study indicates the need for improved IT systems and resources to support their use and this is upheld by the WHO (2021) who stress that further investments may be needed in ICT.

In this study issues with connectivity created a barrier to access for some, in terms of consistent and reliable access to the internet and speedy access to the IT systems to see and add to patient information. The Tech Users Association of New Zealand (TUANZ) usefully differentiate connectivity to include the broadband networks (noting Aotearoa New Zealand has world-class high-speed networks), broadband speed and data limits, and the router being used (TUANZ, n.d.). However, TUANZ also note issues continue with rural connectivity, and this was reflected in the findings of this study.

Preparation for this and future pandemics, and to support the continued use of ICT in nursing practice, has implications for nursing education. The WHO (2021) highlight the importance on ensuring the education of future nurses and midwives prepares them for using ICT. This has been noted internationally (Honey et al., 2017). With ICT being used significantly more in nursing practice, as evidenced in this study, it provides further support to ICT being included more in the preparation of undergraduate nursing students. The importance of ICT, and more broadly nursing informatics, being included in Aotearoa New Zealand undergraduate nursing education had already been recognised with the 2018 publication of Guidelines: Informatics for nurses entering practice (Honey et al., 2018).

Gunawan et al. (2020,) suggest that COVID-19 has brought "both positive and negative, or yin and yang effects" (p. 1515). This study somewhat reflects this dichotomy, though we conclude with this positive comment from one nurse participant:

ICT is great. Instead of seeing it as dehumanising our connections as social beings, we should see it as an opportunity to move forward in this age of technology. [P73]

\section{Limitations}

This exploratory survey recruited participants using a snowballing technique distributed by the authors resulting in 220 responses received. In Aotearoa New Zealand there are 52,000 registered nurses (Nursing Council of New Zealand, 2019), so the sample in this study is very small and caution is needed generalisability. Changes in use of ICT were selfreported during the level 4 and 3 lockdown and need to be treated with some caution. Recommendations are for further research, including repeating the 
survey, distributing it nationally to get a higher response rate, and to assess if changes to nurses' use of ICT has been sustained, or if it has altered as the pandemic situation in Aotearoa New Zealand evolves.

\section{Conclusion}

This exploratory study found access to be key finding. This included access to information technology systems and resources, technical support, connectivity, and ICT having the potential to support access to patients and colleagues. Both barriers and enablers were identified by nurses working with ICT during the lockdown period, but the needs of patients are voiced as a driver for nurses embracing ICT use. This study identifies areas for future research about nurses' use of ICT in their practice but highlights their ability to provide distanced care to patients and embrace technology.

\section{References}

Benner, P. (2000). From novice to expert: Excellence and power in clinical nursing practice. Prentice Hall.

Bokolo, A. J. (2021). Application of telemedicine and eHealth technology for clinical services in response to COVID-19 pandemic. Health and Technology, 11, 359366. https://doi.org/10.1007/s12553-020-00516-4

Bostock-Cox, B. (2020). Changing the way we work: Virtual consultations now and in the future. Practice Nurse, 50(4), 19-22.

Braun, V., \& Clarke, V. (2006). Using thematic analysis in psychology. Qualitative Research in Psychology, 3, 77101. doi: 10.1191/1478088706qp0630a

Buheji, M., \& Buhaid, N. (2020). Nursing human factor during COVID-19 pandemic. International Journal of Nursing Science, 10, 12-24. https://doi: 10.5923/i.nursing.20201001.02

Dykes, S., \& Chu, C. H. (2021). Now more than ever, nurses need to be involved in technology design: Lessons from the COVID-19 pandemic. Journal of Clinical Nursing, 30(7-8), e25-28. https://doi.org/10.1111/jocn.15581

Eddy, C. M. (2021). The social impact of COVID-19 as perceived by the employees of a UK mental health service. International Journal of Mental Health Nursing, 30, 1366-1375. https://doi.org/10.1111/inm.12883

Gunawan, J., Aungsuroch, Y., \& Marzilli, C. (2020). 'New normal' in Covid-19 Era: A nursing perspective from Thailand. Journal of the American Medical Directors Association, 21, 1514-1515. https://doi.org/10.1016/j.jamda.2020.07.021

Holmes, B. (2020). The lessons of COVID-19. The Lamp, $77(2), 5$.

Honey, M., Collins, E., \& Britnell, S. (2018). Guidelines: Informatics for nurses entering practice. University of Auckland. https://auckland.figshare.com/articles/journal contri bution/Guidelines_Informatics for nurses entering_pr actice/7273037

Honey, M., Skiba, D. J., Procter, P., Foster, J., Kouri, P., \& Nagle, L. M. (2017). Nursing informatics competencies for entry to practice: The perspective of six countries. In J. Murphy, W. Goossen \& P. Weber (Eds.), Forecasting informatics competencies for nurses in the future of connected health (pp. 51-61). IOS Press.

Jackson, D., Bradbury-Jones, C., Baptiste, D., Gelling, L., Morin, K., Neville, S., \& Smith, G. D. (2020). Life in the pandemic: Some reflections on nursing in the context of COVID-19. Journal of Clinical Nursing, 29, 20412043. https://doi.org/10.1111/iocn.15257

Meehan, B., \& Honey, M. (2020). Hot tips to assist a virtual patient assessment in uncertain times. Kai Tiaki Nursing New Zealand, 26(3), 18-19.

Ministry of Health. (2021). COVID-19 (novel coronavirus). https://www.health.govt.nz/our-work/diseases-andconditions/covid-19-novel-coronavirus

New Zealand Government. (2020). Alert system overview. Author. https://uniteforrecovery.govt.nz/covid19/covid-19-alert-system/alert-system-overview/

New Zealand Telehealth Forum and Resource Centre. (2021). What is telehealth. Author. http://www.telehealth.co.nz/what-is-telehealth

Nursing Council of New Zealand. (2019). The New Zealand nursing workforce: A profile of Nurse Practitioners, Registered Nurses and Enrolled Nurses 2018 - 2019. Author.

https://www.nursingcouncil.org.nz/Public/Publicatio ns/Workforce Statistics/NCNZ/publicationssection/Workforce statistics.aspx?hkey=3f3f39c4c909-4d1d-b87f-e6270b531145

Nursing Council of New Zealand. (2021). The Nursing Cohort report: A longitudinal study of New Zealand and internationally qualified nurses 2020 Edition. https://www.nursingcouncil.org.nz/Public/Publicatio ns/Workforce Statistics/NCNZ/publicationssection/Workforce statistics.aspx?hkey=3f3f39c4c909-4d1d-b87f-e6270b531145

Polit, D. F., \& Beck, C. T. (2017). Essentials of nursing research: Appraising evidence for nursing practice (9th ed.). Wolters Kluwer Health/Lippincott Williams \& Wilkins.

Tech User Association of New Zealand (TUANZ). (n.d.). Working from home: Have you got the right connectivity? Author. https://tuanz.org.nz/wpcontent/uploads/2020/03/tuanz_wfh_connectivity.pdf

World Health Organization. (2021). WHO Coronavirus (COVID-19) dashboard. Author. https://covid19.who.int/

World Health Organization. (2021). WHO Global Strategic Directions for Nursing and Midwifery 2021-2025. Author. https://cdn.who.int/media/docs/defaultsource/health-workforce/who strategic-directionsfor-nursing-and-midwifery-20212025.pdf?sfvrsn=a5ffe81f 5 \&download=true

Funding: None

Conflict of interest: None 